\title{
An increased prevalence of medical co-morbidities may underscore future growth in the numbers of men requiring penile prostheses
}

\author{
Jason Akerman ${ }^{1}$, Jason R. Kovac ${ }^{2}$ \\ ${ }^{1}$ Department of Urology, McMaster University, Hamilton, Ontario, Canada; ${ }^{2}$ Men's Health Center, Indianapolis, Indiana 46260, USA \\ Correspondence to: Dr. Jason R. Kovac, MD, PhD, FACS, FRCSC. Men's Health Center, 8240 Naab Road, Suite 220, Indianapolis, Indiana 46260, \\ USA. Email: jkovac@urologyin.com. \\ Comment on: Rodriguez KM, Pastuszak AW. A history of penile implants. Transl Androl Urol 2017;6:S851-7.
}

Submitted Nov 15, 2017. Accepted for publication Nov 15, 2017.

doi: $10.21037 /$ tau.2017.11.20

View this article at: http://dx.doi.org/10.21037/tau.2017.11.20

Despite effective oral therapies for erectile dysfunction (ED), a proportion of patients will require additional treatments. For patients who are refractory to non-surgical interventions, insertion of a penile prosthesis remains the gold standard (1). In their review of 'A history of penile implants', Rodriguez and Pastuszak (2) explored the evolution of penile prosthesis design and surgical techniques. Another progression when considering the history of penile prosthetics is the shifting patient demographics of those men requiring penile implantation. Indeed, the worsening health status and increased prevalence of medical co-morbidities that are directly related to the development of ED has the potential to radically increase the amount of men needing penile implants in the future.

Rates of ED and the number of men seeking treatment are expected to continue to grow in the United States over the next few decades (3). Along with an aging population, the prevalence of medical co-morbidities also on the rise. Indeed, many of conditions that are becoming more commonplace in society have been directly implicated in the pathogenesis of ED. Moreover, some of these conditions are also associated with a poor response to firstline therapies like PDE5 inhibitors. This lack of response is known to accelerate the progression of ED and leads to increased utilization of more advanced interventions such as placement of penile prostheses (4-6). Diabetic men, for example, are 1.6-2.1 times more likely to advance to more invasive treatments within 5 years of ED diagnosis, or from the initiation of oral therapy (4).

Indeed, men receiving penile implants from 2001 to
2010 were increasingly sicker with more co-morbidities and lower 10-year predicted survival rates (7). As the number of co-morbid conditions increase, the odds of a patient going on to receive a penile implant should also increase (5). If one examines the patients receiving a penile prosthesis in the United States; hypertension, dyslipidemia, and diabetes mellitus were the amongst the most common co-morbidities (6). Therefore, the number of patients requiring penile prostheses should mirror the increases in these medical co-morbidities.

Early and proper identification of these men should allow practitioners to avoid prolonged trials of less invasive, but more expensive treatments since they are very likely to be ineffective. Identification of these patients early on may help with the development of an under-utilized, but highly effective intervention for $\mathrm{ED}$ - the penile prosthesis.

\section{Acknowledgements}

None.

\section{Footnote}

Conflicts of Interest: The authors have no conflicts of interest to declare.

\section{References}

1. Althof SE, Buvat J, Gutkin SW et al. Sexual satisfaction in men with erectile dysfunction: correlates and potential 
predictors. J Sex Med 2010;7:203-15.

2. Rodriguez KM, Pastuazak AW. A history of penile prosthesis. Trans Androl Urol 2017;6:S851-7.

3. Aytac IA, McKinlay JB, Krane RJ. The likely worldwide increase in erectile dysfunction between 1995 and 2025 and some possible policy consequences. BJU Int 1999;84:50-6.

4. Walsh TJ, Hotaling JM, Smith A, et al. Men with diabetes may require more aggressive treatment for erectile dysfunction. Int J Impot Res 2014;26:112-5.

5. Clavijo RI, Daskivich T, Kwan L, et al. Time course

Cite this article as: Akerman J, Kovac JR. An increased prevalence of medical co-morbidities may underscore future growth in the numbers of men requiring penile prostheses. Transl Androl Urol 2017;6(Suppl 5):S858-S859. doi: 10.21037/ tau.2017.11.20 and predictors of use of erectile dysfunction treatment in a Veterans Affairs medical center. Int J Impot Res 2016;28:167-71.

6. Segal RL, Camper SB, Burnett AL. Modern utilization of penile prosthesis surgery: a national claim registry analysis. Int J Impot Res 2014;26:167-71.

7. Lee DJ, Najari BB, Davison WL, et al. Trends in utilization of penile prostheses in the treatment of erectile dysfunction in the United States. J Sex Med 2015;12:1638-45. 